\title{
Acute Myeloid Leukemia with Minimal Differentiation
}

National Cancer Institute

\section{Source}

National Cancer Institute. Acute Myeloid Leukemia with Minimal Differentiation. NCI

Thesaurus. Code C8460.

An acute myeloid leukemia (AML) in which the blasts do not show evidence of myeloid

differentiation by morphology and conventional cytochemistry. (WHO, 2001) 